\title{
We will now resume our regular programming
}

\section{Thomas Hatch ${ }^{1}$}

Accepted: 7 July 2021 / Published online: 20 July 2021

(c) The Author(s), under exclusive licence to Springer Nature B.V. 2021

The times are always changing. The question this year is whether we can build on some of the changes schools made in the face of the coronavirus and reimagine education altogether. In the first commentary in this series devoted to exploring how schooling might (or might not) change in the wake of the latest pandemic, Zhao and Watterston (2021) highlighted three developments in education that they hope will take hold post-COVID:

- Developmental, personalized, and evolving curriculum;

- Student-centered, inquiry-based, authentic, and purposeful pedagogy; and

- Modes of instruction that capitalize on the strengths of both synchronous and asynchronous learning.

These are not the only possibilities, of course, and the conferences, publications, and conversations already devoted to re-imagining education point to other visions of learning and schooling in the future (see for example Al-Fadala et. al. 2020). Personally, I have expressed the hope that in the future education will:

- "Condense" the school day, supporting much more efficient and equitable academic learning in shorter periods of time and creating room to support a much broader span of developmental goals during the rest of the day;

- Break down the walls of schooling so that students and educators can engage in a wide range of different kinds of learning experiences in their classrooms, in their communities, and beyond; and

- Expand the power of educators by taking advantage of the contributions of tutors, mentors, and multigenerational "learning facilitators" of all kinds (Hatch, 2020).

Regardless, I accept a triple focus on changing curriculum, pedagogy, and mode of instruction as one good foundation for reimagining education that makes creating equitable opportunities and outcomes and uprooting systemic racism a central goal.

Thomas Hatch

hatch@tc.edu

1 Teachers College, Columbia University, New York, NY, USA 
Like many, I am hopeful that we can take advantage of the current moment to make at least a few meaningful steps in some of these directions.

Nonetheless, my work over the past thirty years on school improvement and school reform efforts in the US and in "higher" and "lower-performing" countries also makes me deeply skeptical. Time and again, I have seen how ambitious plans and visions fall short of their aspirations. As a consequence, although I believe this may be a crucial time to ask "What if this is a moment when we can re-imagine education?", I also know that we need to ask a second question: "What if it isn't?" What if, despite the changes wrought by the pandemic, the existing institutional structures, practices, incentives, and beliefs that sustain conventional schooling remain in place?

I don't see this as a pessimistic take. It's imagining the future and understanding the past that enables us to take off on journeys where the exact destination is unknown. When getting ready to climb a mountain, adventurers don't just hope that the path they envision does not lead to an impassible ledge; they don't rely on the hope that the weather will hold. They try to imagine what might happen when they turn a corner or reach a new level, and they get prepared. When the unexpected happens, when the conditions predictably change in unpredictable ways, we need to be ready to respond and rise above.

As my colleagues and I argue in our new book The Education We Need for a Future We Can't Predict (Hatch, Corson, \& Van den Berg, 2021) education systems all around the world find themselves in this situation today. Now more than ever, it's clear that we do not know exactly what lies around the corner, and we cannot determine, with certainty, what today's students will need as adults or what roadblocks or supports societies will put in place for helping them to get there. But we can build on what we know about why it's so hard to improve schools, and we can imagine what it will really take to create more powerful and equitable educational opportunities in the future.

In this commentary, I take up the opportunity to explore what educational change in this pandemic era involves. In the process, I draw particularly on the institutional theories that help me understand why large-scale reform efforts so often fail to live up to their ambitions (Meyer \& Rowan, 1977; Tyack \& Cuban, 1995); on the theories of situated and distributed cognition that informed my training as a developmental psychologist (Salomon, 1983); and on the systems and complexity theories that help explain why mechanistic, linear plans to implement changes have to give way to an understanding of the ever-changing conditions and an embrace of emergent possibilities that cannot be entirely anticipated (Fullan, 2015; Senge, 1990; Wheatley, 1999).

\section{Part 1: Schools don't change unless the conditions do}

Since 2004, I've been teaching a course on School Change, and I used to ask the students to design a school. That assignment required them to follow the basic parameters of the application that New York City used for those who wanted to create new schools (when New York was launching a lot of new schools). But I stopped relying 
on those instructions because that's what the students did: they created new schools, many with the same design features favored at the time including small class sizes, advisory periods, and a focus on personalized, interdisciplinary learning. All of those schools also had interesting, unique features intended to meet the needs of particular groups of students or to match the interests of particular neighborhoods or communities. But every year, at the end of the semester, when the students and I reflected on the designs, many of us noted the same thing: almost every design included groups of students of roughly the same age, with one or maybe two teachers, in a classroom, studying at least some conventional academic subjects. After that realization, I've constantly tried to adjust the parameters of the assignment to encourage students to design "a powerful learning experience" whether or not that experience takes place in a school.

I don't know why it took me so long to realize it, but my work on the school design assignment reminded me of my own experiences working on the ATLAS Communities Project. ATLAS was one of the school designs funded by the New American Schools Design Corporation (NASDC) to "break the mold" of conventional schooling in the early 1990s. ATLAS was a collaboration of four of the leading figures in school reform at the time including James Comer, Ted Sizer, Janet Whitla, and Howard Gardner. That collaboration sought to bring together the resources and expertise of the four organizations they led into one comprehensive and innovative model for a pathway of K-12 schools (for more on ATLAS see Hatch, 1998; Hatch \& White, 2002).

Despite considerable ambition, some previous success, and considerable funding, the effort never took off the way many of us hoped. Many factors contributed to these results, but one factor was that ATLAS, like the other design teams, was asked to produce 44 deliverables every quarter to demonstrate that we were actually doing what we said we would do. This despite the fact that we said that our design would emerge over time from a collaboration with our community partners, not from some top-down pre-determined plan. Furthermore, we explicitly sought to create things like interdisciplinary learning experiences yet NASDC demanded deliverables like curricula in traditional academic subjects including English, math, science, history, and geography. In short, I realized that my students, ATLAS, and the "new" school designers in New York City were all being asked to break the mold of conventional schooling in some ways while conforming to it in others (Hatch, 2001).

Think of it like a set of interconnected circles. Teachers in the classroom are encouraged to personalize learning, support socio-emotional development, or take advantage of new technologies. But for the most part, they are expected to transform their teaching while still operating with the same classrooms, the same groupings of students (in person or online), and the same packed schedule that has always favored direct instruction. Even if teachers are working to change their instructional practices in a school trying to revamp the schedule, to extend the day or year, or to regroup students and teachers, that school still faces the same demands to prepare students for standardized tests, for college, and for the workforce; and, in the US at least, operates within communities marked by segregation, systemic racism, and inequitable access to opportunities for jobs, healthcare, housing, education, and so many other resources and services. 
Simply switching from a focus on designing a school to creating a powerful learning experience does not change all of the challenging conditions in which those experiences take place. But it frees students to focus on key choices: what challenges and goals do they want to pursue and where do they want to do it? In short, changing the requirements provides some flexibility for students to decide which conditions they want to work within. The critical point is that those conditions matter much more than the specific design. If you have a great design-that artfully reimagines every aspect of schooling into a grand new vision for education-but it doesn't fit the conditions, it will fail.

That does not mean that we have to accept every aspect of the conditions or ignore those that are deeply problematic. But we have to figure out how to challenge and work with and around the conditions in order to change them.

\section{Part II: Covid-19, school closures, and stability and change in the conditions for learning}

Tyack and Cuban (1995) provide one perspective that helps explain the stability and incremental changes we see in many of the basic parameters or "grammar" of schooling. Drawing from this perspective points to three critical conditions that explain why some new possibilities for education emerged from the pandemicrelated school closures and why many of those new developments may not stick:

1. Schools fulfill a critical childcare function by housing and watching over children for much of the workday. ${ }^{1}$

2. Schools are expected to prepare students for college and the workforce.

3. "Real school" and "real" learning - the learning that prepares students for college and the workforce-are often equated with conventional academic instruction (Metz, 1989).

The pandemic shutdown of so many schools and workplaces all around the world meant that many children were at home with their families when they normally would have been at school. This radical change opened many people's eyes to the kinds of learning experiences students can have when they are not tied down to a classroom. It also led many school systems to cancel exams and some universities suspended testing-related entrance requirements, all of which lessened the immediate academic pressures on some students and created opportunities to focus more on students' health, well-being, and other aspects of their development.

Even with these dramatic changes in some key conditions, however, expectations about what "real school" looks like contributed to demands for "Zoom school" that followed the regular school schedule and for a continued focus on conventional

\footnotetext{
${ }^{1}$ For a related theoretical perspective, see Christensen and colleagues (2016) work on "jobs to be done theory" which highlights how the need to fulfill particular functions helps to explain some of the challenges and opportunities for innovation in education and business.
} 
school activities and tasks even online. Furthermore, the shutdown led many parents and businesses to recognize how dependent they are on schools to take care of children during the workday and created considerable pressure to keep schools open, to keep students occupied online for hours, or to create "hybrid" approaches that had some students in school and other students on Zoom. (A situation my daughter, a junior in high school, had to deal with that I can only describe as the worst of both worlds.) The continuing concerns about keeping students "on track" to pass tests, graduate, and prepare students for college and the workforce also contributed to mounting pressures to combat "learning loss" (which really should be renamed "loss of time on academic tasks") by intensifying academic work which, in turn, may end up exacerbating the academic pressures that were supposed to be relieved during the pandemic.

When the pandemic ends, some of the changes in conditions may last; but more than likely, at least for the foreseeable future, families and businesses will still need schools to fulfill their childcare function, schools will still need to produce good test scores and students "ready" for college and the workforce, and many of us will continue to have to fight that nagging sense that our children might not be able to keep up with their academically-focused peers if they do not get enough of the "real school" and "real learning" that success in schools seems to require.

Under these conditions what will really change?

\section{Part III: From changes in general to niches of possibility}

Despite these circumstances, my experiences working in and studying a variety of efforts to create more powerful learning experiences in both developed and developing contexts reveals some key principles that can help educators to work around and challenge these conditions (Hatch, Corson, and Van den Berg, 2021). First, new possibilities for schooling are most likely to take off when their goals, capacity demands, and values fit the common needs, existing capabilities, and prevailing conditions in the schools and communities where they're supposed to work. This first principle leads to a corollary or second principle that seems particularly problematic for those who want to reimagine schooling altogether: the more radical our visions are for education and the more they diverge from conventional practice, the less likely they are to take hold on a large scale. However, that does not mean that it is impossible to pursue the new visions for education that Zhao and Watterston and others imagine. It means that the demands and pressures of conventional schooling make it easier to bring those visions to life in particular circumstances and contexts-ecological "niches" in a sense-rather than across entire school systems. This tension between the nature and extent of reform efforts yields the third principle and opens up another avenue for change: there are places- "niches of possibility" - where the conditions are more amenable for transforming education.

This "niche" approach suggests a shift in focus from creating strategies for personalized or student-centered learrning that are supposed to work in general, for all subjects and topics, all the time, to developing specific innovations and adaptations-new resources, services and activities - that support learning of certain 
topics, with particular groups of students, at particular points in time. In a sense, it means that instead of trying to scale-up initiatives across often inhospitable conditions, we need to "plug-in" to places where the goals, needs, capabilities and values already provide some support for more powerful learning.

Although those who pursue educational alternatives often seek to start their own schools or programs in places outside the typical bureaucracies of public schooling (Hatch, 2021), niches of possibility can be found all over. For example, the Beam Center began by creating a camp in New Hampshire in the US that engaged youth in working with artists and craftspeople to create large-scale art installations. Those "learning productions" enabled youth to develop their interpersonal, cognitive and creative capacities in collaborative efforts to build things like a "Pipe Tree" - a fully functioning pipe organ nestled among (and shaped like) the trees in the surrounding forest. But Beam has also gone on to create "fab labs" in a number of schools in New York City that make it possible for teachers to create these same kinds of "learning productions" during the regular school day.

Jo Boaler and colleagues have developed a variety of tools and activities that enable teachers to support the development of conceptual understanding of critical concepts like number sense within the conventional curriculum. These include a set of cards, with each one showing different mathematical representations and operations. Students scan the cards laid out in front of them, identify those that are equivalent (such as $3+3+3,3 \times 3$, and 9) and explain how they came up with their answer (Boaler, 2015). By adapting a familiar set of materials, flash cards, the activity enables teachers to take a problematic conventional routine that demands quick recall into an opportunity to develop deeper understanding by exploring the relationships between different mathematical operations.

These kinds of local adaptations and inventions can be found all over the world in developed and developing contexts. Second Chance, for example, has created a whole set of materials, activities, and supports designed initially for contexts in Ethiopia, where many young children have been out of school for years. Despite difficult conditions, Second Chance created a 10-month curriculum with an activity-based pedagogy in which students work with objects and materials from their local environment-including sticks, stones, and clay-sorting, grouping, and experimenting, making observations, recording findings and discussing them with peers and facilitators. With limited access to teacher preparation institutions and those institutions focused on conventional instruction, Second Chance could not find or rely on a regular source of qualified teachers. Nonetheless, they were able to take advantage of the local circumstances and found that unemployed youth who know the local language and have at least a 10th grade education can excel in leading Second Chance classrooms and in facilitating student learning. In turn, to support those facilitators after hiring, Second Chance created a succinct set of professional learning activities that can be carried out quickly and in conjunction with the 10-month curriculum. With this approach, Second Chance has served more than 135,000 children in Ethiopia, Liberia, and Lebanon, with their graduates completing primary school at nearly twice the rate of children in local government schools (Akyeampong et al., 2018; Simpson, 2019). 
These learning productions, fab labs, number cards and the activity-based pedagogy and related supports are "micro-innovations"-adaptations and inventions new to the contexts in which they are developed. They take advantage of the specific conditions and exploit previously untapped "affordances" (Gibson, 1977) that support deeper learning even as many of the forces that support rote instruction remain in place.

These micro-innovations can be shared across contexts, but within predictable constraints. The cards can be used by many different teachers working on number sense and related concepts with students early in their mathematical development; but the cards aren't likely to be as useful in other subjects or to work as well with more advanced mathematical concepts. Second Chance probably won't "scale" easily to settings where students are already in school, and Second Chance has even found that expanding to sites with large numbers of out-of-school youth like Liberia and Lebanon requires them to make numerous adaptations to match the specific local circumstances (Hatch et al., 2021). Yet, both the number cards and activitybased pedagogy and related materials and services contribute to the development of the materials, expertise, and networks of relationships that support the emergence of more powerful learning experiences all around the world. As Cohen, Spillane, and Peurach (2018) have described it, these developments help to establish the infrastructure that supports substantive, though usually incremental, improvements in instruction that in turn can provide the foundation for educational transformation over the long term.

From this perspective, the specific vision for learning remains important, but that vision has to be accompanied by the recognition that it is not the vision itself that will change schools; schools will be transformed, over time, with changes in the conditions and the construction of the infrastructure for more powerful learning. Rather than aiming to develop a program and scale it across contexts, the focus shifts to the student level and to making sure that all students, particularly those left out and systematically disadvantaged by conventional schooling, encounter more and more opportunities inside and outside schools to engage in powerful learning experiences. Those experiences create new emergent possibilities for education that build directly on the specific conditions in which students live and learn every day.

\section{Conclusion}

Reimagining education for the future goes hand-in-hand with recognizing the specific conditions within which that learning will take place. The work to figure out how to take advantage of those conditions and build the infrastructure for more powerful learning in every community fuels bottom-up system change. But education leaders play a crucial role in ensuring that those bottom-up developments lead to more equitable opportunities and outcomes across communities. Real leadership involves learning how to follow: listening to what's happening on the ground and sharing the power that makes it possible for local communities to create the conditions for their own success. It means that instead of focusing on creating more and more initiatives designed to change the system, leaders need to help monitor the 
conditions, ratchet down the pressures that impede the development of more powerful and more equitable learning opportunities, and embrace those conditions that can support it.

Far from an "anything goes" or "let all flowers bloom" approach, however, education leaders and the organizations they lead are also essential for creating the mechanisms that can bring people together in and across communities:

- Regular opportunities for education stakeholders to come together at the local, regional, and national level to revisit their education goals and develop a common understanding of the purposes of education and collective responsibility for achieving them (Hatch, 2013);

- Sophisticated formative assessments, diagnostic tools, surveys, and new representations of teaching and learning that make it possible to reflect on and develop a shared understanding of students' experiences in and out of school; and

- Community partnerships that enable those working in different sectors to join in collaborative efforts that enhance their collective impact on children's development.

These mechanisms play a crucial role in building the relationships in and across contexts that can ensure that those systematically disadvantaged by conventional schooling get equitable access to much more powerful learning experiences.

Yet, at the same time, the need to engage diverse viewpoints and bring people together contributes to the challenges in pursuing visions for the future substantially different from the present reality. The challenges that even "top-performing" countries face in trying to shift to support the development of "21st Century Skills" and provide a more holistic approach to education provide a case in point. In Finland, proposals to change from a curriculum focused on conventional subjects to one requiring inter-disciplinary or "phenomena-based teaching" were part of the nationwide of curriculum "renewal" in 2004, but were never adopted. Twelve years later, in 2016 in the next curriculum renewal process, that same change was discussed again in stakeholder groups around the country. At that time a change was made in the national curriculum framework, but it was only a small step requiring that all students experience at least one inter-disciplinary learning module every year. This approach can "nudge" the system (as one Finnish policymaker described it to me) and supports incremental change over the long-term, but those "nudges" remain unlikely to induce a dramatic short-term transformation.

Recognizing all of the conditions and pressures that support the status-quo and make it difficult to put in place new visions for learning at any significant scale in short periods of time yields a final principle for improving schools: Schools are most likely to change in concert with other changes in society. Despite the oft-repeated hope that somehow education systems can be a lever for transforming economies and societies overall, "top-performing" systems like Finland and Singapore evolved over a period of 30 to 40 years in ways that are intimately connected to developments in other aspects of their societies. (For a related perspective, see educational explorations of concepts related to "punctuated equilibrium" borrowed from evolutionary biology such as Holyoke et al., 2009; Marsh et al., 2021; Murphy, 2016). 
As a consequence, in addition to working locally to build the infrastructure for more powerful learning in each and every community, educators, students, and community members also need to join together to create the social movements that can change the conditions in which children live and learn (Rincón-Gallardo, 2019). Like the climate change movement, social movements to create equitable educational opportunities and outcomes cannot achieve their goals in a few years following the pandemic. We have to develop the urgency to eradicate the beliefs, structures and practices that maintain inequitable societies, and we have to foster the relentless drive to sustain this movement across generations.

\section{References}

Akyeampong, A., Delprato, M., Sabates, R., James, Z., Pryor, J., Westbrook, J., Humphreys, S., \& Tsegay, H. (2018). Speed School Programme in Ethiopia: Tracking the progress of Speed School students 2011-2017. Research report. Falmer, Brighton, UK: University of Sussex Centre for International Education.

Al-Fadala, A., Kirby, J., Zaki, O., Baghdady, A., \& Regester, D. (2020). Education disrupted, education reimagined. Doha, Qatar: WISE - Qatar Foundation.

Boaler, J. (2015). Fluency without fear: Research evidence on the best ways to learn math facts. YouCubed.org. https://www.youcubed.org/evidence/fluency-without-fear

Christensen, C., Hall, T., Dillon, K., \& Duncan, D. S. (2016). Competing against luck: The story of innovation and customer choice. Harper Business.

Cohen, D. K., Spillane, J. P., \& Peurach, D. J. (2018). The dilemmas of educational reform. Educational Researcher, 47(3), 204-212.

Fullan, M. (2015). The new meaning of educational change (Fifth ed.). New York City: Teachers College Press.

Gibson, J. J. (1977). The theory of affordances. In R. Shaw and J. Bransford (Eds.), Perceiving, acting, and knowing: Toward an ecological psychology (pp. 67-82.) Hillsdale, NJ: Lawrence Erlbaum Associates.

Hatch, T., with Corson, J. \& Van den Berg, S. (2021). The education we need for a future we can't predict. Thousand Oaks, CA: Corwin.

Hatch, T. (2021). Expanding the boundaries of learning. Phi Delta Kappan, 102(8), 8-13.

Hatch, T. (2020). Small steps to big changes in schools. International Education News. https://inter nationalednews.com/2020/09/02/small-steps-to-big-changes-in-schools/

Hatch, T. (2013). Beneath the surface of accountability: Answerability, responsibility and capacity building in recent educational reforms in Norway. Journal of Educational Change, 14(1), 1-15.

Hatch, T. (2001). What does it take to break the mold? Teachers College Record, 102(3), 561-589.

Hatch, T. (1998). The differences in theory that matter in the practice of school improvement. American Educational Research Journal, 35(1), 3-31.

Hatch, T., \& White, N. (2002). The raw materials of reform: Rethinking the knowledge of school improvement. The Journal of Educational Change, 3(2), 117-134.

Holyoke, T., Henig, J., Brown, H., \& Paquet, N. (2009). Policy dynamics and the evolution of state charter school laws. Policy Sciences, 42(1), 33-55.

Marsh, J. A., Allbright, T. N., Brown, D. R., Bulkley, K. E., Strunk, K. O., \& Harris, D. N. (2021). The process and politics of educational governance change in New Orleans, Los Angeles, and Denver. American Educational Research Journal, 58(1), 107-159.

Metz, M. H. (1989). Real school: A universal drama amid disparate experience. Politics of Education Association Yearbook, 75-91.

Meyer, J. W., \& Rowan, B. (1977). Institutionalized organizations: Formal structure as myth and ceremony. American Journal of Sociology, 83(2), 340-363.

Murphy, J. (2016). The evolution of the high school in America. Teachers College Record, 118, 1-18. 
Rincón-Gallardo, S. (2019). Liberating learning: Educational change as social movement. New York, NY: Routledge.

Salomon, G. (Ed.) (1983). Distributed cognition. Cambridge, UK: Cambridge University Press.

Senge, P. (1990). The fifth discipline: The art and practice of the learning organization. Doubleday.

Simpson, A. (2019). Endline evaluation, Luminos Fund Second Chance Program, Liberia. Boston, MA:

Luminos Fund. https://luminosfund.org/wp-content/uploads/2018/11/QA_Second_Chance_Endli ne_Evaluation_Report_2018-19_Final.pdf.

Tyack, D. B., \& Cuban, L. (1995). Tinkering toward utopia: A century of public school reform. Harvard University Press.

Wheatley, M. J. (1999). Leadership and the new science. Berrett-Koehler.

Zhao, Y., \& Watterston, J. (2021). The changes we need: Education post COVID-19. Journal of Educational Change, 22, 3-12.

Publisher's Note Springer Nature remains neutral with regard to jurisdictional claims in published maps and institutional affiliations. 